\title{
Distribution of Responsibility for Climate Change within the Milieu
}

\author{
Laÿna Droz
}

Citation: Droz, L. Distribution of Responsibility for Climate Change within the Milieu. Philosophies 2021, 6, 62. https://doi.org/10.3390/ philosophies6030062

Academic Editors: Erik Persson, Åsa Knaggård and Kerstin Eriksson

Received: 25 May 2021

Accepted: 15 July 2021

Published: 28 July 2021

Publisher's Note: MDPI stays neutral with regard to jurisdictional claims in published maps and institutional affiliations.

Copyright: (C) 2021 by the author. Licensee MDPI, Basel, Switzerland. This article is an open access article distributed under the terms and conditions of the Creative Commons Attribution (CC BY) license (https:// creativecommons.org/licenses/by/ $4.0 /)$.
BC3 Basque Centre for Climate Change, 48940 Leioa, Spain; layna_droz@yahoo.fr

\begin{abstract}
This article approaches the challenges of the distribution of responsibility for climate change on a local level using the framework of the milieu. It suggests that the framework of the milieu, inspired by Japanese and cross-cultural environmental philosophy, provides pathways to address the four challenges of climate change (global dispersion, fragmentation of agency, institutional inadequacy, temporal delay). The framework of the milieu clarifies the interrelations between the individual, the community, and the local milieu and is open to a conservative view of human communities and an inclusive view of multispecies communities. On this basis, an account of individual responsibility that is anchored in the local milieu and includes a responsibility to collaborate across milieus is developed. It consists of a forward-looking responsibility that balances a degree of contributory responsibility for one's imprints on the milieu with a degree of capacity-responsibility that varies regarding the individual's knowledge and powers, and the acceptability of practices within the local milieu.
\end{abstract}

Keywords: climate change; responsibility; distribution; agency; mitigation; adaptation; milieu; environmental ethics

\section{Introduction}

A key challenge of the question of responsibility for climate change is the global dispersion of its causes and its effects [1-4]. This leads to a fragmentation of the agency of those who contributed to causing climate change and of identifying who are the key agents best placed to take action to mitigate and adapt to climate change [5-7]. Meanwhile, most human legal and social institutions are adapted to territorially bounded communities with clear borders and designed to isolate perpetrators who have a direct and significant causal relationship to the harm. Several authors indicate that there is an institutional inadequacy to tackle phenomena such as climate change [8,9]. Last but not least, a temporal challenge of climate change complexifies further the situation: climate change effects are persistent, nonlinear and time delayed [10]. These four challenges (global dispersion, fragmentation of the agency, institutional inadequacy, temporal delay) set the stage for the question of how responsibility for climate change should be distributed.

The question of responsibility distribution for climate change matters because climate change has harmful impacts on human health and on other species' health and habitats [11]. Climate change has been shown to be closely interlinked with land degradation [12], biodiversity loss [13] and food and water security [14]. Environmental processes are highly complex and tend to be mutually reinforcing and influenced by direct and indirect drivers at various scales [15]. The impacts of climate change can affect individual human health, as well as individual projects, livelihood, and the community. They change the possible ways of life within a particular territory, the places, milieus, and ecosystems, the feasibility of projects, and other species.

As climate change is a global issue, it is crucial to recognize the diversity of ethical systems around the world before assigning responsibilities for climate change. Responsibility is a question of ethics, which is rooted in local sociocultural contexts and varies greatly depending on the context and the people. The impacts of climate change also influence 
these sociocultural contexts and the local landscapes and milieus in which communities live. The intertwinements between local communities, their natural environment and socio-cultural contexts and the individual perspective can be captured by the concept of milieu.

This article approaches the distribution of responsibility for climate change at a local level using the framework of the milieu. It focuses on individual ethical responsibility, as the (relational) individual decision maker is a primary locus of ethical agency. It suggests that the framework of the milieu can provide pathways to address the four challenges of climate change. Inspired by Japanese and cross-cultural environmental philosophy, the framework of the milieu was developed [16] to clarify the interlinkages between the individual, the community, and the local milieu and to identify possible pathways for sustainability while considering "the extent of diversity of human ways to live with nature" [17]. This paper presents a framework of the milieu open to a conservative view of human communities and an inclusive view of multispecies communities. On this basis, an account of individual responsibility that is anchored on the local milieu but includes a responsibility to collaborate across milieus is developed to address the challenges of assigning ethical responsibility for climate change.

\section{The Framework of the Milieu}

The idea of milieu builds on the work of several scholars, from the paradigm of possibilism of the French Vidal de la Blache (1845-1918) [18] to one of the founders of ecology Jakob von Uexküll (1864-1944) [19], as well as on the works of naturalists such as Buffon (1707-1788) [20,21]. A crucial contribution was made by the Japanese philosopher Watsuji Tetsurō (1889-1960). His key concept of "fûdo", rooted in the ancient Chinese word pronounced $f \bar{e} d \check{u}$, is composed of the characters for the wind and for the soil. It is so closely related to climate that the first translation of his eponymous book into English translated directly "fûdo" as "climate". Yet, the concept of "fûdo", hereafter translated as "milieu" [22], goes far beyond the idea of climate [23]. The first line of Wastuji's Fûdo reads [24]:

"I use our word Fûdo, which means literally, "Wind and Earth", as a general term for the natural environment of a given land, its climate, its weather, the geological and productive nature of the soil, its topographic and scenic features."

Wastuji develops the idea of milieu (fûdo) and describes it as the "environment" as we perceive it through a web of significations and symbols from the standpoint of a subjective human being. He uses the example of the cold that we do not feel as an " $\mathrm{I}$ " independent subject alone confronted to coldness as an object, but that we experience together with others within the milieu, and which leads us to take actions-e.g., wear clothes-and to adopt ways of life-e.g., build houses and collect wood. Phenomena of the milieu, like the cold, are "ways of human self-understanding" [25]. They have a history for we, humans, have developed webs of practices, values and usages of the milieu through time across generations [26]. Human communities have developed sociocultural and technological practices and worldviews in a continuously ongoing process of adaptation to the local climate and milieu.

I propose to see the milieu as the intermediate layer between our subjective standpoint and the environment that we cannot access directly and neutrally. We cannot live outside of the environment, but we are perceiving and acting in it as a milieu laden with meanings and values. Neither can we live outside of a milieu. In other words, being in a milieu is central to being human. We live through dynamic cycles of codetermination with the milieu. Augustin Berque (1942-) uses the ideas of matrix and imprint to designate these constant movements of identification and differentiation between the self and the milieu [27]. Our ways of life leave traces on the milieu-imprints-and our surroundings shape our behaviours and our identities, like a matrix that nurtures and constrains us. Watsuji insists on the dynamicity of the cycles of codetermination between the self and the milieu, he therefore rejects natural determinism and adopts a conception of the self as 
relational [28]. He also describes the diversity of cultures anchored in different milieus, and how these mutually shape each other [29]. Nevertheless, like most of the past philosophers, he seems to assume that cultures are directly linked to bounded communities grounded in a particular land. For our contemporary use in this paper, this is an important limitation of his work, along with the absence of mention of responsibility and of internal mechanisms of oppression and domination within communities. In today's globalized context, any ethic aiming at assigning responsibility for environmental harm needs to address these issues.

The framework of the milieu meets this need by clarifying the relationships that bound together the individual, the milieu as imprint, the community and the milieu as matrix. The objective of the framework of the milieu is not to be faithful to the insights of the pioneers of the concept of milieu, but to propose a development inspired by them and to apply it to issues of contemporary environmental ethics, such as landscape sustainability [17] and individual responsibility for climate change as developed in this paper. The framework of the milieu goes one step further from Watsuji Tetsuro's idea of milieu and Augustin Berque's concept of matrix-imprint and describes a process (see Figure 1): The community (more or less deliberately) shapes the surrounding environment through habits and repeated practices over time. Doing so, the community builds the milieu as matrix, like a nest to nurture its members. In turn, the milieu as a matrix nurtures, guides and constrains the practices of its inhabitants. The individual grows and lives constrained, guided and inspired by the web of norms and meanings of the milieu. Within this matrix, the individual agent retains a relative flexibility to make reflexive ethical choices. Every individual behaviour then leaves imprints on the milieu, like footsteps in the milieu that remain even after one has taken the next step. Individuals necessarily use some elements of their milieu to sustain themselves, from picking up plants to eat to having a lifestyle supported by a complex social structure. Finally, the whole of the individual imprints of the inhabitants of the milieu shapes and changes the milieu. The milieu is maintained and changed through the intertwined imprints of multiple agents who interact with each other and with the milieu.

Figure 1 sketches the framework of the milieu. It describes the relationships between the individual, the community and the milieu. The individual grows, acts and thinks from within the milieu as a matrix that nurtures, constrains and guides her. Most individual behaviours leave imprints on the milieu that maintain and change the milieu, together with the multiple imprints of the community who shares a particular milieu. Figure 1 synthesizes the phenomenological perspective of the individual who is influenced by and acts within the milieu (upper left); the spatial aspect of the global interconnection of the milieus that lead to distant consequences of individual imprints (lower left); the community and the institutional and sociocultural aspect of the milieu (lower right); the milieu as a matrix made of the countless influences of multiple human and nonhuman agents through time, and that, in turn, nurtures and constrains its inhabitants (upper right). Source: Original by the author.

Imprints are understood here as all the traces left on the milieu by the ways of life of a group or of an individual. This wide-encompassing concept includes traces left not deliberately by habits and omissions. Watsuji did not use the matrix-imprint bivalence in his description of the milieu. Yet, he mentions briefly the word "imprint" to warn us against the risk of opposing human activities and a passive natural environment [30]. According to him, we should not misunderstand the relation between the group and the milieu as if the landscape were the result of groups "trying to make the shadow of themselves cast on a particular nature last forever". Watsuji notes that it is possible to approach the alterity and outside character of the concept of environment by an abstraction process. For example, natural sciences attempt to reach the neutral reality of environmental phenomena by minimizing as much as possible interferences from human experience. Indeed, while we always grasp the world through the intersubjective filter of the milieu tainted by the cultural context, the quest of natural sciences can be understood as to avoid cultural relativism by constructing another mode of intersubjectivity. Still, Watsuji warns 
that we should not forget two things. On the one hand, this environment is the result of the "expressions of human existence"; that is the side of the imprint in our framework. On the other hand, we should not forget that the "subjectivity of human existence can only be grasped from within" the landscape and the environment, which echoes the matrix side of the milieu in our framework. By pairing the idea of imprint with the idea of matrix, the framework of the milieu avoids the risk of objectifying the environment and abstracting a subject-object relation.

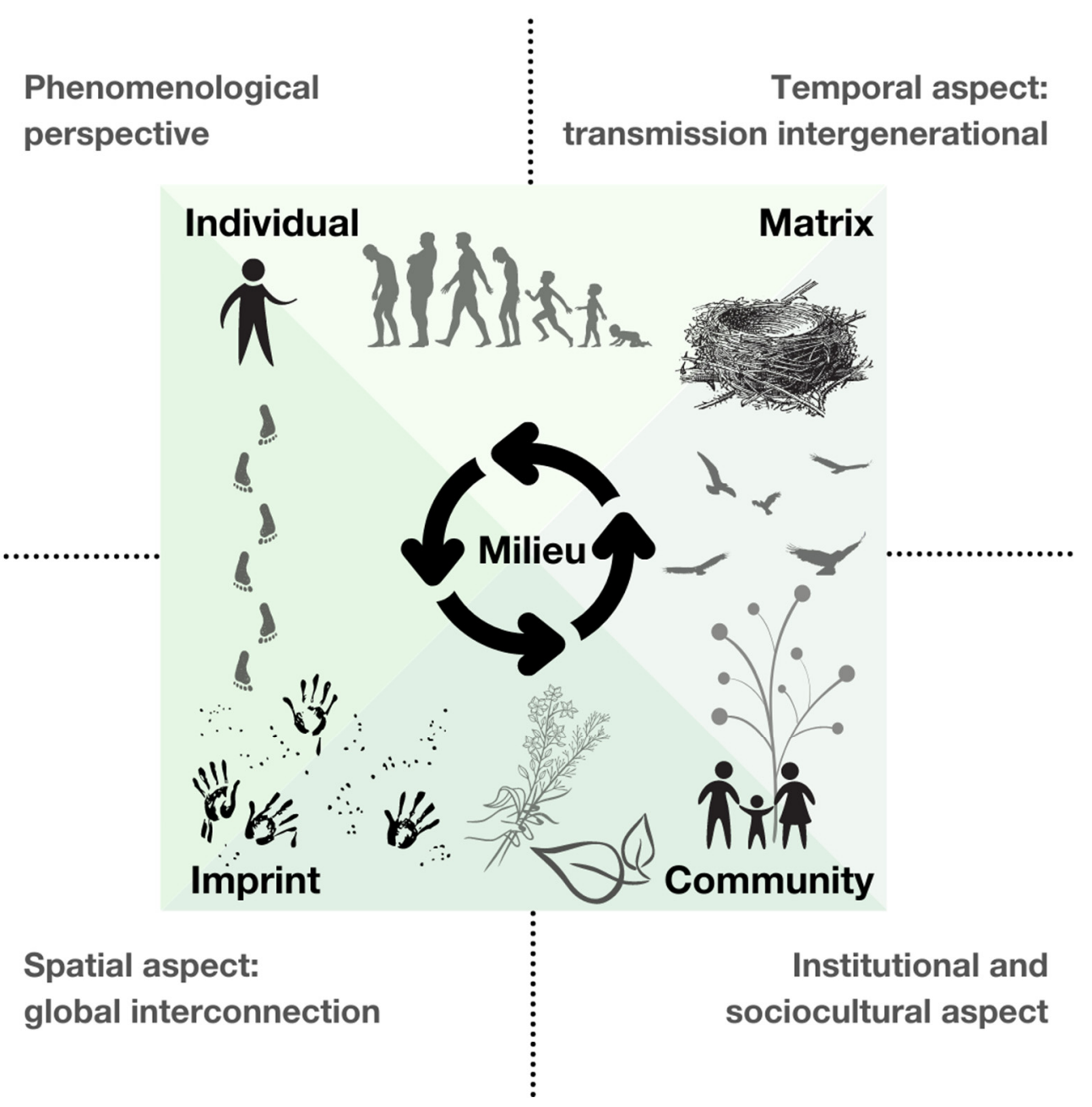

Figure 1. The framework of the milieu.

The framework of the milieu includes four closely intertwined aspects. Each of these aspects distinguishes the idea of milieu from the concept of environment.

1. Phenomenological perspective. The conceptual framework of the milieu distinguishes the perspective of the phenomenological agent who inherits of a particular sociocultural milieu which roots her identity and informs her practices, from the intergenerational collective historical processes that contribute to building the medial matrix. It emphasizes the experience of the individual as the ground for external ethical action on the milieu. In contrast, the environment is usually taken to be neutrally and objectively accessible, regardless of the internal state of the agent and perceiver.

2. Institutional and sociocultural aspect. The concept of milieu highlights the mutual cyclic relationships that bind together individual human beings, communities, other nonhuman living beings and their surroundings, including the natural environment. This view rejects radical individualism as well as the common connotation of the environment as an over-objectified passive receptacle. As individual human beings, 
we are all born into a specific place within a particular social structure and milieu that nurtured us. The organization of this particular matrix, both in terms of social contracts and in terms of usages of the land, is the fruit of the ways of life of past generations inhabiting the place, and of their interactions with travellers and other groups elsewhere. This process unfolds over time, and that is what Watsuji refers to as historicity. He notes that "we live with the past human beings within us", and that this "rich past content without limits that defines the present" is the source of the present "unity of the ethical social organization" [30]. For Watsuji, the social organization is multilayered, spanning from the scales of the family, the village, up to the scale of the nation, and ethics emerges from the relations that bind together the members of these communities [31].

3. Spatial aspect and global interconnection: The borders of milieus are porous, and they are closely interconnected in a global network continuously crossed by various flows (air, nutrients, goods, ideas, etc.) While milieus are local, they are constantly influenced and influencing distant milieus, as it clearly appears with global environmental changes such as climate change, and with the ubiquity of the internet and communication media. Spreading through the multiple connections of this network and amplified by collective practices, in some cases such as climate change, the consequences of one individual imprint can be said to reach a global scale. This third characteristic insists on the interdependence of locally rooted milieus and distinguishes it from the concept of environment which, by virtue of already being an abstraction, can be uprooted into the idea of "global environment".

4. Temporal aspect and intergenerational transmission: Milieus are characterized by their inherent dynamic changes. No milieu is fixed and permanently stable. The milieu is continuously changing through a historical process that unfolds across generations and composes the norms, usages and meanings in which human beings live in the present. This contrasts with the idea of a pristine original nature to which we couldor could not-return. The milieu changes through the multiple interactions of its human and nonhuman inhabitants. In place of the picture of a linear evolution from a state of nature to a human-controlled world, the concept of milieu sets the stage for a constantly evolving and changing world in which multiple species adapt themselves, interact and shape their world.

To summarize, milieus are built in mutual cyclic relationships, experienced by phenomenological agents, connected globally in a dynamic network, and continuously changing. The medial matrix is shaped through historical processes that involve countless interactions of people in past generations, between each other and with their own milieu, nonhuman living beings, and natural environment.

These four aspects of the framework of the milieu echo the four challenges of assigning responsibility for climate change (Table 1). The challenge of global dispersion of causes and effects of climate change is reflected in the spatial aspect of the global interconnection of milieus. An account of individual responsibility for imprints on the milieu-including imprints that are spatially and temporally distant-will be developed to address this challenge. The challenge of temporal delay of the effects of climate change is also addressed by the account of individual responsibility presented below. Moreover, shifting the focus from the individual lifespan to the temporal aspect of the milieu and the intergenerational transmission of healthy and meaningful milieus helps soften this challenge. The third challenge of fragmentation of the agency regarding climate change adaptation and mitigation at the subnational level is tackled by focusing on the individual human being as the locus of the ethical agency and by including a responsibility to collaborate with others within individual responsibility for climate change. Before dwelling into the account of individual responsibility grounded in the framework of the milieu, it is necessary to clarify what counts as a community within the framework of the milieu, in other words, who is a member of the community and what are the borders of this community. This question is rooted in the institutional and sociocultural aspect of the framework and partially mirrors 
worries that existing institutions are inadequate to tackle the challenges presented by climate change.

Table 1. Four challenges for assigning responsibility for climate change and pathways for sustainability.

\begin{tabular}{|c|c|c|c|}
\hline $\begin{array}{l}\text { The Framework of } \\
\text { the Milieu }\end{array}$ & $\begin{array}{c}\text { Four Aspects in the } \\
\text { Framework of the Milieu }\end{array}$ & $\begin{array}{l}\text { Four Challenges for Assigning } \\
\text { Responsibility for Climate Change }\end{array}$ & Pathways for Sustainability \\
\hline Imprint & $\begin{array}{l}\text { Spatial aspect and global } \\
\text { interconnection }\end{array}$ & global dispersion & $\begin{array}{l}\text { Individual responsibility for } \\
\text { imprints }\end{array}$ \\
\hline Individual & Phenomenological perspective & fragmentation of agency & $\begin{array}{l}\text { Individual responsibility to } \\
\text { collaborate within and across } \\
\text { milieus }\end{array}$ \\
\hline Matrix & $\begin{array}{l}\text { Temporal aspect and } \\
\text { intergenerational transmission }\end{array}$ & temporal delay & $\begin{array}{c}\text { Transmission of meaningful } \\
\text { milieus as matrices } \\
\text { (sustainability) }\end{array}$ \\
\hline Community & $\begin{array}{c}\text { Institutional and sociocultural } \\
\text { aspect }\end{array}$ & institutional inadequacy & $\begin{array}{l}\text { Multispecies and human } \\
\text { communities }\end{array}$ \\
\hline
\end{tabular}

Table 1 synthesizes the four facets of the framework of the milieu (imprint, individual, matrix and community) and the four aspects that they reflect (a spatial aspect, the phenomenological perspective, a temporal aspect, and an institutional and sociocultural aspect), and mirrors them to the four challenges for assigning responsibility for climate change (global dispersion, fragmentation of the agency, temporal delay and institutional inadequacy), and the pathways for sustainability developed in this article in response to these challenges. Source: Original by the author.

\section{Multispecies and Human Communities}

What counts as a community in the framework of the milieu is deliberately kept vague, as it takes very different shapes and forms depending on the case to which the framework is applied. Still, insofar as the historical processes that create the medial matrix involve multiple living beings over countless generations, they are "collective". In general, the community refers mainly to the people who share and inhabit a particular milieu. The literature on the milieu tends not to address other-than-human species and to keep what counts as "human community" ambiguous, while refraining from differentiating individuals from the groups or to draw clear borders to groups.

We can distinguish two views regarding who makes up the community. A more conservative view restricts the community to the people who inhabit a specific milieu. The inclusive view interprets it as a multispecies community that includes all living beings who share and inhabit a milieu, human and other-than-humans. Whichever view is taken, it is clear that nonhuman living things take active part in the dynamics of milieus and in networks connecting milieus across the globe (e.g., migratory species). Like humans, nonhuman living things are shaped by their environment and are shaping it by their usage, consuming food, building shelters and leaving faeces. They are also impacted by and impacting environmental changes. Nonhuman living things thus play an active role in shaping the milieus lived by human beings. They can become central parts of the cultural imaginary and ways of life of sociocultural groups. Interacting with animals and other nonhuman natural elements will influence the worldview and imaginary of an individual human. Domestic animals and crops illustrate of how nonhuman living things are closely intertwined with meanings, values and worldviews of sociocultural groups. Yet, they do not deliberately and directly take part in shaping values and meanings shared by human communities.

Through time, the human and multispecies communities shape the local milieus as matrices that will guide the individuals' behaviors and practices [32,33]. For instance, paths, bridges and buildings restrain and guide the movements of individuals within a particular place. Likewise, plants and animals influence the behaviours of human individuals, who might seek the shades of a tree, admire a shrub of wildflowers, or avoid a wasps' nest. Usages and stories by past human individuals also help shape the matrix of the milieu we are living in today by transmitting webs of symbols and significations that structure our present sense-making. 
The framework of the milieu rests on a conception of the human individual as relational [34]. Identities, ways of life, ideas and practices are built in relation with othershumans and other-than-human $[35,36]$. We construct ourselves intertwined in constitutive relations with others and with the milieu. Physically and mentally, the individual cannot be abstracted from the milieu and the environment. These "others" include relatives and people close to us, but also people whose works contribute and influence us, such as the farmers who produced the food we eat and the singer of our favourite song. In an inclusive view, these others also encompass other-than-human living things, such as key landscape elements (trees, flowers, gardens, etc.) [37], pets, domestic animals, and the multitude of diverse other species that live near or within us, that we might not even notice, but on some of which we depend (insects, microorganisms, plants, etc.) [38]. In this sense, we could say that we are living in-and thanks to-continuous relationships with multispecies societies.

Nevertheless, this constitutive relationality of the individual self does not erase the agency. The individual preserves the capacity to reflect and choose among the possibilities of actions and opinions offered by the milieu. In particular, the individual also retains the possibility to resist complying with a dominant practice in her milieu, even if the failure to follow this practice might imply some social risks such as criticisms and persecution [39]. Thus, the phenomenological agent and her individual imprints crucially differ from the community's collective imprints insofar as the individual is a decision-maker capable of reflexive choices. While Watsuji tends to insist more on how the milieu influences, constrains and shapes the individual self, it is crucial for us to highlight the space of choice and freedom that remains for the individual to be able to reflect, act ethically and be responsible.

In the globalized context, individuals are interconnected in webs reaching around the globe far beyond their milieu. On the one hand, more and more people are nowadays travelling and migrating beyond their original local milieu, and they are being influenced by faraway milieus through communication media and the internet [40]. On the other hand, the imprints of one's way of life are not limited to their immediate milieu, but they can have consequences in distant environment, through global mechanisms such as the international economic ties or climate change. To use the framework of the milieu to assign responsibility for environmental harm that spans across large distances such as climate change, we need to take the context of globalization into account. Two aspects of globalization are particularly relevant: deterritorialization and interconnectedness [41]. First, in the line of the challenge of global dispersion of climate change effects and causes, deterritorialization [42] due to the ubiquity of long-distance transportation and communication challenges the common assumption of limiting the reach of ethics and responsibility to within given territorially bounded communities. Second, systems and people are increasingly interconnected, which led some to argue that there is no "global", but only interconnected locals, coining the word "glocal" [43]. These two aspects are not limited to human communities, but they also impact other species, as exemplified by the issue of invasive alien species, which is one of the five main direct drivers of biodiversity loss at the global level [13]. Other species take advantage of human transportation to migrate or are forcefully introduced by legal or illegal wildlife trafficking to new ecosystems.

A milieu is always rooted locally in a perspectival individual existence. In the easiest case of bounded human communities that coincide with a specific milieu, the sedentary individual lives and acts ethically informed, constrained and guided by the consensual significations and practices of this milieu. Yet, individuals are rarely attached exclusively to a single bounded community anchored in one local milieu. Instead, individuals are shaped by multiple milieus as matrices. Individuals carry a multiplicity of milieus: birthplace, travel places, workplaces, current living places, etc. By travelling and moving, some individuals are influenced by other milieus. By meeting other travellers, the individual enters in contact with their respective significant milieus, for which one cares because they are part of the identity of the cherished others [28]. By interacting with other distant 
communities through communication media, individuals are also influenced by their imaginaries and practices, and by the fate of their milieus.

Deterritorialisation and interconnectedness highlight the issue of multiplicity of memberships to different communities and milieus, and the possibility to be part of communities that are seemingly a-spatial with cyber networking. One could argue that deterritorialisation and aspatial cybernetworking threaten the relevance of the milieu as a matrix shaping individuals' worldview and behaviour. To answer briefly, yes, globalization exacerbates exchanges and contacts between different milieus. However, the milieu where the individual exists and acts still plays a crucial role, because it shapes the individual behaviour more than any other distant influences, by restraining appropriate practices and possible usages of the space.

\section{Imprints on the Milieu and Ethical Responsibility}

Humans have always left imprints on their milieu. Nowadays, however, the imprints that most of us leave on the environment have more impacts than ever, and an individual can leave imprints far from the local milieu one lives in. This is reflected in the challenge of global dispersion of causes and effects of climate change. Individual agents leave significant imprints on milieus simply by virtue of being a member of a social structure [44], regardless of their intentions, awareness, knowledge, etc. For example, an infant already has mediated impacts on the milieu, because she is taken as a future potential consumer in market analysis deciding of the quantity of production of some goods, leading to further depredation of natural resources. One's appearance, social role and body language also have influences on others' behaviours. By being somewhere, one individual even influences the behaviours of animals. Then it comes as no surprise that even one's inaction and passivity have impacts on the milieu, including on distant milieus where the individual will never set foot.

Within the framework of the milieu, sustainability and environmental harm are directly connected to individual agency. The wide scope of what counts as a medial imprint brings us to a first crucial yet controversial conclusion, namely, that all these elements (actions, but also ways of life, omissions, etc.) should be included as possible objects of responsibility ascription for environmental harm [45]. When thinking about ethics, the milieu as an imprint is the expression of the agency of the individual. Conversely, the milieu as a matrix can appear as a set of constraints. In summary, the individual is shaped by influences from multiple milieus and communities. And the individual is leaving traces, some harmful, in multiple milieus, including in spatially and temporally distant milieus. Then, ethical responsibility for distant harm comes from the fact that the individual (even passively and not deliberately) contributes to leaving traces on this distant milieu. This contributory responsibility varies in degrees, depending on the number of interventions by other agents in the causal chain, regardless of the temporal and spatial distances between the agent and the harm.

In short, the capacity of the individual to be responsible is constrained by the milieu as a matrix, and her contributory responsibility amounts to her imprints on the milieu. The individual responsibility for an environmental harm depends on her causal contribution to the harm (imprint), and on her capacity to act otherwise, that is, to take effective reparative or adaptive actions (matrix). Both capacity responsibility and contributory responsibility vary in degree and weight differently on the balance of responsibility for every individual [46]. Within the limits of her capacity, the individual is responsible for engaging in the practices that leave the least harmful imprints on the milieu.

Capacities are largely determined by the milieu. Three criteria affect the capacity of the agent, each of them directly related to aspects of the milieu as a matrix (see Figure 2). First, the state of knowledge of the agent and her capacity to imagine alternatives are mainly determined by how she makes sense of the world [47] and the cultural imaginary she is in $[48,49]$, both of which are features of the milieu as a matrix. Second, the ease with which the agent could actually change her behaviour depends directly on the social acceptability and availability of alternative practices that also are part of the milieu as a 
matrix. Finally, powers and vulnerabilities of the agent are determined by the milieu she is in, and her position in her community [50-52].

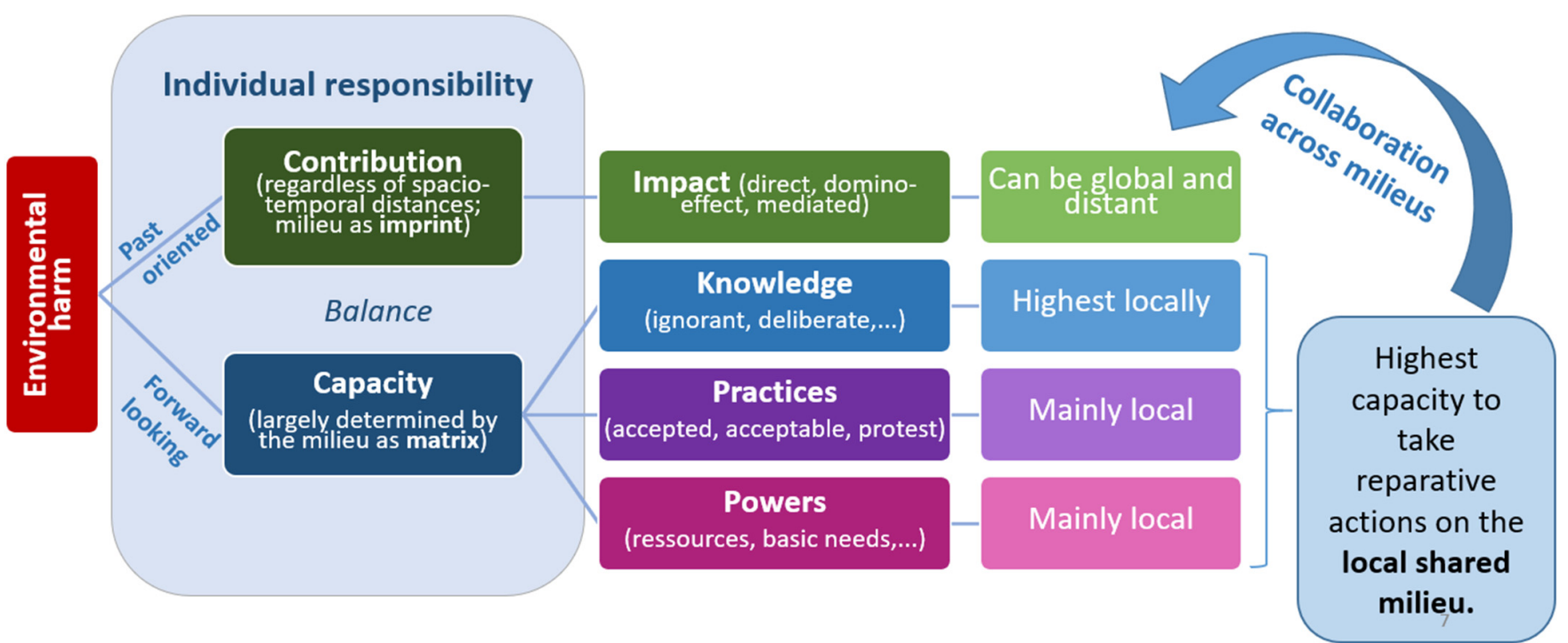

Figure 2. Responsibility for environmental harm and reparative actions. Source: Droz, L. The Concept of Milieu in Environmental Ethics: Individual Responsibility Within an Interconnected World. Routledge: Oxon, United Kingdom, 2021, p. 158. Sketches the account of individual responsibility for environmental harm. Individual responsibility results from the balance between past-oriented contributory responsibility and forward-looking capacity responsibility. The individual contribution to environmental harm amounts to the impacts of the individual ways of life, including omissions and domino-effect consequences. These harmful impacts can be global and distant. Yet, the capacity of an agent largely depends on her knowledge, available practices and her powers, which are all mainly rooted in the local milieu. As a result, the individual has the highest capacity to take reparative actions on the local shared milieu. To face the global consequences of distant impacts, collaboration across milieus is necessary.

As the milieu is local, so are most of the capacities of the agent. Generally, with the notable exception of scientific knowledge, the agent knows better her own milieu, so her capacity to find better solutions to environmental problems is higher in her own milieu. The agent also knows better the local practices than practices in distant milieus. She is best placed to estimate what alternative practices she could adopt and to assess the social acceptability of these practices. Plus, to be a member of the same community and to share largely overlapping milieus are crucial elements when it comes to judging, advising and criticizing others' practices. Generally, we are more prompt to trust and to accept advice from people who are close to us and who share similar ways of life and struggles, than from strangers. As a result, it is easier for the agent to change her practices and to discuss of practices locally than to attempt to intervene in distant places [53].

Most of the powers of the agent are anchored in the local milieu. For agents owning or having legal rights to use some strips of land, they can control its sustainable usage. Their practices on the land have direct consequences, and so they have full responsibility about it (unless they are constrained by others to use it in certain harmful ways). Many people purchase commodities that are produced with high impacts on the environment, such as agricultural goods. As buyers, they can also influence these local markets and boycott commodities with highest environmental impacts. Further, most of the social resources of the agent are also mainly local, such as reputation, power to influence others, right of vote, etc. The most powerful impacts that an agent can have tend to be limited to the local scale, even if some actions can influence distant milieus, such as boycott affecting production plans. 


\section{Collaboration across Milieus}

Within the framework of the milieu, individual responsibility does not end with what the individual can do alone. Some actions must be discussed, decided on and coordinated with others, and the individual has a responsibility in engaging in fruitful dialogue to foster such common actions. As a member of a community who enacts and designs some practices and ways of life in a milieu, one has a communal responsibility, shared with others, for the relations that she builds with others and her milieu [54]. It aims at changing the imprint of the community as a whole, by empowering others to increase their capacity to uphold their own individual responsibilities, and by taking common actions together. These depend strongly on the relatively flexible position and role the individual holds in the community.

Collaborating with others is crucial especially because feelings of powerlessness are often mentioned as the main hindrance preventing the agents to change behaviours towards more sustainable lifestyles $[55,56]$. Social sciences show that the main obstacle to take proenvironmental behaviour is often not the lack of environmental awareness or irrationality, but it is the fact that "the power to make a significant difference, one way or the other, to global or even local environmental change, is immensely unevenly distributed" [57]. If these findings point out to the need for common actions, they do not exclude individual actions, especially if we understand individuals as relationally developing their positions and powers within the group [58]. Yet, agents often use observations regarding the uneven distribution of powers within the group as an excuse to avoid taking responsibility [59]. They might delegate the responsibility to take communal actions to individuals whose roles are apparently more powerful or hierarchically higher (e.g., government officials or private company executive officers). Additionally, they might reify social processes leading to the harmful practices and to the uneven distribution of power, claiming that "nobody can do anything about it".

When recognizing the extent to which their individual actions matter in the global picture, individual agents might find themselves overwhelmed and withdraw to care only about the immediate demands of their close surroundings. Often criticized as egoistic and self-centred, this tendency to care for what is closer to us might not be as negative as this, precisely because the scope of what we most immediately care about coincides with the scope of our highest capacity. Most of our care and capacity are likely to be located and projected on our local milieu [54]. This tendency to care primarily for what is close might also positively limits us from intervening in distant milieus and imposing on distant others our own values and ways of thinking. In our interconnected world, it might be a crucial safeguard because ultimately, as Anton Sevilla warns, "no matter how one may try to examine other cultures (or other fūdo [milieus]) objectively, one is always viewing it from one's own context, one's one fūdo [milieu]" [60].

Due to the close interconnectedness of today's world, the positive effects of local actions may benefit distant milieus, be it direct or mediated by others' actions, in the same ways harmful effects can contribute to causing environmental disasters in distant milieus. If coincidental influences through people and media relaying successful distant sustainable projects do not seem sufficient to tackle environmental problems of a global scope and unprecedented severity, voluntary collaboration across milieus is another option, for example through global networks that foster exchange of skills and knowledge to develop sustainable projects.

\section{Pathways to Address the Four Challenges of Distribution of Responsibility for Climate Change}

Four challenges for assigning responsibility for climate change were mentioned in the introduction: global dispersion of its causes and effects, fragmentation of the agency, institutional inadequacy, and temporal delay of the effects. These four challenges are closely intertwined and mutually reinforcing each other. The framework of the milieu 
offers lenses to approach this bundle of challenges by clarifying the relationships between the individual, the community, and the local milieu.

From this perspective, any individual that contributes directly or indirectly to climate change leaves imprints on milieus that can be distant spatially and temporally, and must engage in collaborative actions to fulfil its individual responsibility for these imprints, to the extent of her capacity. In the account of responsibility presented in this paper, spatial and temporal distance between the individual action and the environmental harm to which it contributed do not matter in terms of the degree of contributory responsibility of the individual. The challenge of global dispersion is therefore addressed by means of scientific assessment of the probable consequences of one's practice, wherever or whenever these consequences might occur. Crucially, the degree of individual contributory responsibility that comes from this assessment is to be balanced with a degree of capacity-responsibility to take reparative actions. The capacity of an agent to act responsibly depends on several factors that pertain to the milieu as a matrix: the knowledge of the agent regarding the consequences and the possible alternative practices, the social acceptability and accessibility of less harmful alternative practices, and the powers of the agents, in terms of basic needs and resources.

The challenge of the fragmentation of the agency to tackle climate change adaptation and mitigation is approached by focusing on the individual as the locus of ethical agency, with a conception of the individual as concretely relational, which leads to the conclusion that individuals have a responsibility to collaborate within their own milieu, and possibly across milieus. The specific types of collaboration are to be decided by discussion between stakeholders within the respective milieus and can include networks, coalitions, public-private partnership, strategic alliances, sister cities, etc. The most appropriate form of collaboration for climate change mitigation and adaptation within a particular milieu depends on local sociocultural and political aspects as well as on the specificities of the concrete issues in each case. Yet, for any intervention that might span beyond one's own milieu, utmost care must be taken not to overstep the other milieus' sociocultural particularities. Instead, the account of responsibility developed in this article urges individuals to act locally to improve the milieu they live in. By collaborating between milieus, local common actions can reach the global scope necessary to tackle climate change mitigation. The temporal delay of the effects of climate change that emerge from individual actions in the past or in the present does not present a particular challenge in the wide-encompassing account of individual responsibility within the framework of the milieu. Indeed, the temporal distance between the action and the harm is irrelevant to the attribution of a degree of contributory responsibility to an individual's way of life. Moreover, if we shift the focus from the contribution to climate change to the actions needed for mitigation and adaptation, the issue of temporal delay of the effects vanishes, too. The account of individual responsibility presented in this article is forward-looking; it focuses on the actions and habits each of us can and should take within the limits of our degree of capacity. Finally, the question can be reframed in terms of what we want to maintain, and what meaningful milieu we want to co-create and transmit. In this sense, the time-related questions of climate change impacts on the local milieu amount to discussions of what nurturing milieus as matrices we sustain and develop to transmit to future generations.

The challenge of institutional inadequacy at the local level can hardly be addressed abstractly, for any solution for it would rely on local sociocultural and political specificities. It raises questions regarding who is part of the local community that shares the milieu and what mechanisms of decision making are developed within the milieu. Here is not the place to enumerate mechanisms of decision making and their potential advantages and disadvantages for climate change adaptation and mitigation. Instead, this paper's discussion of human and multispecies communities that shape milieus opens venues to include within the explicit decision-making mechanisms of a human community other forms of negotiations that are attentive to other species' needs and usages of the milieu. Ways of negotiating usages of the place with other species with whom we share the milieu 
could be reimagined. Several recent works explore this venue [35,61-64], and if a more detailed account of these pathways lies beyond the scope of this article, it could be a fascinating direction for future research.

Finally, the focus on individual ethical responsibility does not exempt other entities from being subjected to other types of responsibilities and duties (including legal liability) such as States and companies; neither does it conflict with legal tools such as environmental rights. Any institution or organization, such as states, governments or private companies, is composed of individual decision-makers who are situated within the webs of their milieu and taking decisions through the decision-making rules of their organizations. The account of individual responsibility for environmental harm applies to government officials or private company executive officers, who will have a higher degree of contributory and capacity responsibility for environmental harm than a lambda citizen with very little sociopolitical and economic power [65]. For example, in contrast with the executives of fossil fuel companies who have a very high degree of contributory and capacity responsibility for harm induced by climate change, the individual car owner who consumes and relies on the work of these companies has a lesser degree of responsibility for this harm, but nevertheless retains a degree of individual responsibility to opt out from unsustainable practices and engage in reparative actions such as boycotting these fossil fuels companies and use political and legal tools to hold them accountable and change the social structure. In this sense, the account of individual responsibility defended in this paper is complementary to the development of legal tools such as environmental rights. Yet, these legal tools like environmental rights, their interpretation and their implementation depend on legal systems and sociocultural frames, and therefore vary highly from milieu to milieu. The focus on the ethical responsibility of the individuals deliberately avoids to rest on an idea of universal rights; but it does not conflict with adopting environmental rights and State top-down duties within specific milieus (nations, states, etc.). Furthermore, States are not necessarily the unique or best scale at which sustainable change can happen, and the account of responsibility in terms of milieu supports the possibility for sustainable transformative changes to be driven at the local scale by the community inhabiting a particular milieu.

\section{Conclusions}

To face climate change, we are called to make ethical judgements about practices that cause harm far away from us. This paper develops "the framework of the milieu", a tool to address normative questions about our relation to nature and to others' worldviews. Inspired by an idea of the Japanese philosopher Watsuji Tetsurō, the milieu refers to the geographical and historical matrix shaping human behaviours and identities, and to the imprints of human groups. By describing how individuals are shaped by the local milieu and how they act on it as nexus of ethical agency, the framework of the milieu offers a basis for environmental ethics across scales, from global to local. Within this framework, individual responsibility for climate change is wide-encompassing (including ways of life, inaction and omissions) and forward-looking - it urges to improve our ways of life in the line of climate change adaptation and mitigation. Globalization multiplies the interconnections between communities and individuals belonging to different milieus, but it does not erase the crucial role of the local milieu that constrains, guides and supports individuals' behaviours.

The concept of milieu prevents uniformization and domination across communities and groups. Hierarchical and oppressive organizational patterns are highly likely to remain within groups, and other theoretical tools are needed to address them. These tools, such as participatory decision-making mechanisms to foster collaboration within and across milieus, will need to be developed through discussions within each milieu, as social hierarchies and organizational structures cannot be artificially separated from their historical and cultural contexts to be discussed abstractly. Our analysis of the concept of milieu gives a safeguard against some worrying political and economic trends to intervene 
in far distant areas in the name of environmental protection. Every milieu is characterized by different systems of values and ways of life from which individuals can innovate and design locally and culturally appropriate sustainable ways of life, while asking advice from independent scientific experts. Further, the concept of milieu can prevent utilitarian analyses blinded by cost-efficiency calculations by integrating from the very start the subjectivity of ethical values and usages of the place. Besides, it does not exclude the fact that some milieus might advocate a strong dualism between humans and nature, but it takes such as dualist stance as a locally anchored worldview, not as a universal objective truth. As such, the concept of milieu can be a useful tool to integrate diverse environmental ethics in our contemporary globalized context.

The dynamicity of milieus also justifies sustainable changes. Indeed, the milieu is not a fixed image of ways of life and values from the past. Instead, it is an ever-changing web of meanings that are adapted by the currently living individuals to better fit their needs and values. Then, if it is necessary and urgent to renounce some seemingly old traditions and replace them with more sustainable practices, this should not be considered as a regrettable loss or a threat to a supposedly stable harmony, but as an expression of the ongoing relationships between living individuals and their long-lasting milieus. Behavioural changes towards more sustainable ways of life can be seen as a normal evolution emerging from the cyclic relation we weave with our milieu, and not as the reluctant results of an exceptionally constraining ethical duty. Nowadays, when it comes to the ways we interact with our environment, change is not to be feared as much as passive and harmful inactivity.

Funding: This research was funded by the Swiss National Science Foundation, Grant N P2SKP1_194948.

Acknowledgments: A previous version of this paper was presented at the Asian Conference on Ethics, Religion and Philosophy, 21-23 March 2019, in Tokyo, Japan, and was significantly improved thanks to the comments of the participants. This paper also benefited from precious inputs from the preliminary "Fuudo" research project team at the Research Center for Humanity and Nature in Kyoto, Japan, in particular Miyata Akihiro, Ota Kazuhiko and Anton Sevilla.

Conflicts of Interest: The author declares no conflict of interest.

\section{References}

1. Attfield, R. Mediated Responsibilities, Global Warming, and the Scope of Ethics. J. Soc. Philos. 2009, 40, 36-225. [CrossRef]

2. Armstrong, C. Climate Change and Justice. In Oxford Research Encyclopedia of Politics; Oxford University Press: New York, NY, USA, 2017. [CrossRef]

3. Cripps, E. Climate Change and the Moral Agent: Individual Duties in an Interdependent World; Oxford University Press: New York, NY, USA, 2013.

4. Briggle, A. Thinking through Climate Change: A Philosophy of Energy in the Anthropocene; Palgrave Macmillan Palgrave Studies in the Future of Humanity and Its Successors; Springer Nature: Cham, Swirtzerland, 2020. [CrossRef]

5. Vanderheiden, S. Climate Change and Collective Responsibility. In Moral Responsibility Library of Ethics and Applied Philosophy; Vincent, N.A., Ed.; Springer: Dordrecht, The Netherlands, 2011.

6. Tan, K.C. Individual Duties of Climate Justice under Non-Ideal Conditions. In Climate Change and Justice; Moss, J., Ed.; Cambridge University Press: Cambridge, UK, 2015. [CrossRef]

7. Kent, J. Individualized Responsibility and Climate Change: 'If Climate Protection Becomes Everyone's Responsibility, does It End up Being No-One's?'. Cosmop. Civ. Soc. J. 2009, 1, 132-149.

8. Gardiner, S.M. A Perfect Moral Storm: Climate Change, Intergenerational Ethics and the Problem of Moral Corruption. Environ. Values 2006, 15, 397-413. [CrossRef]

9. Knaggaard, A.; Persson, E.; Eriksson, K. Sustainable Distribution of Responsibility for Climate Change Adaptation. Challenges 2020, 11, 11. [CrossRef]

10. Jonas, H.; Verantwortung, D.P. Versuch Einer Ethik Für Die Technologische Zivilisation; Insel Verlag: Frankfurt, Germany, 1979.

11. Henning, B.G.; Walsh, Z. Climate Change Ethics and the Non-Human World; Routledge: London, UK, 2020.

12. IPBES. The IPBES Assessment Report on Land Degradation and Restoration; IPBES Secretariat, UNEP: Bonn, Germany, 2018.

13. IPBES. The Global Assessment Report on Biodiversity and Ecosystems Services; IPBES Secretariat, UNEP: Bonn, Germany, 2019.

14. IPCC. Climate Change and Land: An. IPCC Special Report on Climate Change, Desertification, Land Degradation, Sustainable Land Management, Food Security, and Greenhouse Gas. Fluxes in Terrestrial Ecosystems; IPCC Secretariat: Geneva, Switzerland, 2019.

15. Harris, G. Seeking Sustainability in an Age of Complexity; Cambridge University Press: Cambridge, UK, 2007. 
16. Droz, L. The Concept of Milieu in Environmental Ethics: Individual Responsibility within an Interconnected World; Routledge: Oxon, UK, 2021.

17. Chakroun, L.; Droz, L. Sustainability through Landscapes: Natural Parks, Satoyama, and Permaculture in Japan. Ecosyst. People 2020, 16, 378. [CrossRef]

18. De La Blache, P.V. Le Principe de La Géographie Générale. In Annales de Géographie; Armand Colin: Paris, France, 1896; Volume 5, pp. 129-142.

19. Schroer, S.A. Jakob von Uexküll: The Concept of Umwelt and Its Potentials for an Anthropology beyond the Human. Ethnos 2021, 86, 132-152. [CrossRef]

20. Canguilhem, G.; Savage, J. The Living and Its Milieu. Grey Room 2001, 7-31. [CrossRef]

21. Farber, P.L. Buffon and the Concept of Species. J. Hist. Biol. 1972, 5, 259-284. [CrossRef]

22. Watsuji, T. Fūdo, Le Milieu Humain (A. Berque, Trans.); CNRS Editions: Paris, France, 2011.

23. McCarthy, E. Watsuji Tetsurō The Mutuality of Climate and Culture and an Ethics of Betweenness. In The Oxford Handbook of Japanese Philosophy; Oxford University Press: New York, NY, USA, 2019.

24. Watsuji, T. Milieu Fuudo, Ningengakuteki Koosatsu; Iwanami Bunko: Tokyo, Japan, 2004.

25. Mayeda, M. Time, Space and Ethics in the Philosophy of Watsuji Tetsuro, Kuki Shuzo, and Martin Heidegger, 1st ed.; Routledge: London, UK, 2015.

26. Watsuji, M. Milieu Fuudo, Ningengakuteki Koosatsu; Iwanami Bunko: Tokyo, Japan, 2004; pp. 17-18.

27. Berque, A. Médiance, de Milieux En Paysages; Belin/Reclus: Paris, France, 2000.

28. Droz, L. Watsuji's Idea of the Self and the Problem of Spatial Distance in Environmental Ethics. Eur. J. Jpn. Philos. 2018, 3, 145-168.

29. Kazuhiro, O. Critical Cosmopolitanism and Fudo Theory: Tetsuro Watsuji and Alfred Schütz. Comp. Stud. 2018, 45, 73-81.

30. Watsuji, T. Ethics (Rinrigaku), First Published between 1937 and 1949; Iwanami Bunko: Tokyo, Japan, 2007; pp. 315-316.

31. Carter, R. Introduction to Watsuji Tetsuro Rinrigaku. In Watsuji Tetsuro's Rinrigaku: Ethics in Japan; SUNY Press: New York, NY, USA, 1996.

32. Centemeri, L. Commons and the New Environmentalism of Everyday Life. Alternative Value Practices and Multispecies Commoning in the Permaculture Movement. Rass. Ital. Sociol. 2018, 59, 289-314. [CrossRef]

33. Houston, D.; Hillier, J.; MacCallum, D.; Steele, W.; Byrne, J. Make Kin, Not Cities! Multispecies Entanglements and “BecomingWorld" in Planning Theory. Plan. Theory 2018, 17, 190-212. [CrossRef]

34. LaFleur, W. An Ethic of As- Is: State and Society in the Rinrigaku of Watsuji Tetsurō. In La Société Civile Face à l'Éat Dans Les Traditions Chinô̂se, Japonaise, Coréenne et Vietnamienne; Vandermeersch, L., Ed.; Études Thématiques 3; École Française d'Extrême-Orient: Paris, France, 1994; pp. 443-464.

35. McCarthy, E. Ethics Embodied: Rethinking Selfhood through Continental, Japanese, and Feminist Philosophies; Lexington Books: Lanham, MD, USA, 2010.

36. Sevilla, A.L. Cultural-Moral Difference in Global Education: Rethinking Theory and Praxis via Watsuji Tetsurô. Educ. Stud. Jpn. 2018, 12, 23-34. [CrossRef]

37. Stenseke, M. Connecting "Relational Values" and Relational Landscape Approaches. Sustainability Challenges: Relational Values. Curr. Opin. Environ. Sustain. 2018, 35, 82-88. [CrossRef]

38. Gilbert, J.A.; Blaser, M.J.; Caporaso, J.G.; Jansson, J.K.; Lynch, S.V.; Knight, R. Current Understanding of the Human Microbiome. Nat. Med. 2018, 24, 392-400. [CrossRef]

39. Haslanger, S. What is a Social Practice? R. Inst. Philos. Suppl. 2018, 82, 231-247. [CrossRef]

40. Bennett, W. Communicating Global Activism. Inf. Commun. Soc. 2003, 6, 143-168. [CrossRef]

41. Scheuerman, W. Globalization. In The Stanford Encyclopedia of Philosophy; Edward, N., Zalta, W., Eds.; Metaphysics Research Lab, Stanford University: Stanford, CA, USA, 2018. Available online: https:/ / plato.stanford.edu/archives/win2018/entries/ globalization/ (accessed on 28 January 2021).

42. Deleuze, G.; Guattari, F. Mille Plateaux et Schizophrénie 1; Editions de Minuit: Paris, France, 1980.

43. Wellman, B. Little Boxes, Glocalization, and Networked Individualism. In Digital Cities II: Computational and Sociological Approaches; Tanabe, M., Besselaar, P., Ishida, T., Eds.; Springer: Berlin/Heidelberg, Germany, 2002; pp. 10-25. [CrossRef]

44. Haslanger, S. Distinguished Lecture: Social Structure, Narrative and Explanation. Can. J. Philos. 2015, 45, 1-15. [CrossRef]

45. Cullity, G. Acts, Omissions, Emissions. In Climate Change Justice; Moss, J., Ed.; Cambridge University Press: Cambridge, UK, 2015. [CrossRef]

46. Droz, L. Environmental Individual Responsibility for Accumulated Consequences. J. Agric. Environ. Ethics 2020, 33, 111-125. [CrossRef]

47. De Jaegher, H.; Paolo, E.D. Participatory Sense-Making. Phenomenol. Cogn. Sci. 2007, 6, 485-507. [CrossRef]

48. Anderson, B. Imagined Communities: Reflections on the Origin and Spread of Nationalism; Verso: London, UK, 1983.

49. Castoriadis, C. L'institution Imaginaire de la Société; Seuil: Paris, France, 1975.

50. Misztal, B. The Challenges of Vulnerability: In Search of Strategies for a Less Vulnerable Social Life; Palgrave Macmillan: London, UK, 2011. [CrossRef]

51. Shue, H. Climate Justice: Vulnerability and Protection; Oxford University Press: Oxford, UK, 2014.

52. Pelluchon, C. Taking Vulnerability Seriously: What does It Change for Bioethics and Politics. In Human Dignity of the Vulnerable in the Age of Rights; Springer: Cham, Switzerland, 2016; Volume 55, pp. 293-312. [CrossRef] 
53. Kymlicka, W. Liberalism, Community, and Culture; Clarendon Press: Oxford, UK, 1991.

54. Goodin, R. Green Political Theory; Polity Press: Cambridge, UK; Cambridge, MA, USA, 1992; Volume 32.

55. Parkin, S. The Positive Deviant: Sustainability Leadership in a Perverse World; Routledge: London, UK, 2010.

56. Jasper, J.M. The Art of Moral Protest: Culture, Biography, and Creativity in Social Movements; University of Chicago Press: Chicago, IL, USA, 1997.

57. Kollmuss, A.; Agyeman, J. Mind the Gap: Why do People Act Environmentally and What are the Barriers to Pro-Environmental Behavior? Environ. Educ. Res. 2002, 8, 247. [CrossRef]

58. Reiff, M. Terrorism, Retribution, and Collective Responsibility. Soc. Theory Pract. 2008, 28, 209-242. [CrossRef]

59. Young, I.M. Responsibility for Justice; Oxford University Press: Oxford, UK, 2010; pp. 158-170.

60. Sevilla, A.L. Watsuji Tetsurô's Global Ethics of Emptiness: A Contemporary Look at a Modern Japanese Philosopher; Global Political Thinkers; Palgrave Macmillan: New York, NY, USA, 2017; Volume 169. [CrossRef]

61. Multispecies Cities, WORLD WEAVER PRESS. Available online: http://www.worldweaverpress.com/store/p176/Multispecies_ Cities.html (accessed on 27 April 2021).

62. Rupprecht, C.D.D.; Vervoort, J.; Berthelsen, C.; Mangnus, A.; Osborne, N.; Thompson, K.; Urushima, A.Y.F.; Kóvskaya, M.; Spiegelberg, M.; Cristiano, S.; et al. Multispecies Sustainability. Glob. Sustain. 2020, 3. [CrossRef]

63. Lorimer, J. Gut Buddies: Multispecies Studies and the Microbiome. Environ. Humanit. 2016, 8, 57-76. [CrossRef]

64. Gabrysch, S. Imagination Challenges in Planetary Health: Re-Conceptualising the Human-Environment Relationship. Lancet Planet. Health 2018, 2, 72-73. [CrossRef]

65. Droz, L. Challenging harmony to save nature? Environmental activism and ethics in Taiwan and Japan. Int. J. Crime Justice Soc. Democr. 2021, 10. [CrossRef] 